\title{
Antimicrobial Activity of Antimicrobial Peptide LPcin-YK3 Derived from Bovine Lactophoricin
}

\author{
Ji-Sun Kim ${ }^{1}$, Ji-Ho Jeong ${ }^{1}$, Jang-Hee $\mathrm{Cho}^{2}$, Dong-Hee $\mathrm{Lee}^{2}$, and Yongae Kim ${ }^{1 *}$ \\ ${ }^{1}$ Department of Chemistry, Hankuk University of Foreign Studies, Yong-In 17035, Republic of Korea \\ ${ }^{2}$ Biomaterial Research Center, Cellinbio, Suwon 16681, Republic of Korea
}

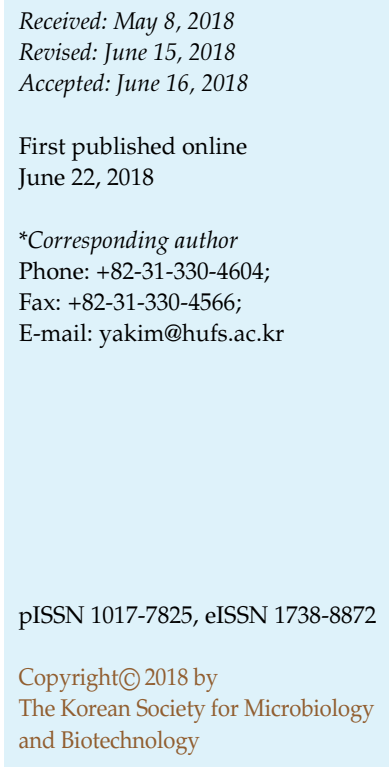

\begin{abstract}
We previously reported on lactophoricin (LPcin), a cationic $\alpha$-helical antimicrobial peptide derived from bovine milk, which has antimicrobial effects on Candida albicans as well as Grampositive and Gram-negative bacteria. In this study, we designed the LPcin-YK3 peptide, a shorter analog of LPcin, and investigated its antimicrobial activity. This peptide, consisting of 15 amino acids with +3 net charges, was an effective antimicrobial agent against the on the Gram-positive strain, Staphylococcus aureus (MIC: $0.62 \mu \mathrm{g} / \mathrm{ml}$ ). In addition, the hemolytic activity assay revealed that the peptide was not toxic to mouse and human erythrocytes up to $40 \mu \mathrm{g} / \mathrm{ml}$. We also used circular dichroism spectroscopy to confirm that peptide in the presence of lipid has $\alpha$-helical structures and later provide an overview of the relationship between each structure and antimicrobial activity. This peptide is a member of a new class of antimicrobial agents that could potentially overcome the problem of bacterial resistance caused by overuse of conventional antibiotics. Therefore, it could be used as a therapeutic or natural additive, particularly in the cosmetics industry.
\end{abstract}

Keywords: Cationic $\alpha$-helical antimicrobial peptide, antimicrobial activity, hemolysis, natural preservatives, therapeutic additives

\section{Introduction}

It is important to develop novel classes of antimicrobial agents and find new compounds for universal use in particular to fill a clinical need caused by the increase in resistant microorganisms due to overuse of antibiotics. Thousands of antimicrobial peptides (AMPs) represent an abundant and diverse group of natural molecules that have now been discovered in a variety of plants, vertebrates, and invertebrates [1]. These AMPs have a variety of functions, the most notable of which is that they possess activities against a wide range of microorganisms, including Gramnegative/-positive bacteria, fungi, and protozoa as well as human cancer cells $[2,3]$. The high potential of these peptides as a new generation of promising antimicrobial agents is widely acknowledged [4,5], and some of them are well-known as food additives, as well as being used in the cultivation of plants and pharmaceutical industries [6,7]. These peptides also have been used by the cosmetics industry for personal care products such as lotions, creams, ointments, wound dressings, natural preservatives and ingredients [8]. For example, consumers prefer to use natural additives to synthetic additives like paraben esters, methylisothiazolinone and so on. Besides, the public pressure in many countries has led to an assertion that the use of synthetic ingredients should be prohibited because of harmful effects, even though these additives are limited used in cosmetics. For these reasons, the numerous applications of AMPs as consumer-friendly alternatives to synthetic additives are certain to become more popular with consumers.

Human skin naturally possesses AMPs such as defensins, cathelicidin, dermcidin and lactoferricin which serve important roles for the innate and/or adaptive immune skin immunity [9]. AMPs in the human skin, also known as host defense peptides, can act directly and indirectly to eliminate microbial flora. Once microbes have invaded the primary epithelial barrier ie, the skin, increased AMP 
production has been shown to be important for killing of bacteria. Induced AMPs can stimulate the neutrophilmediated phagocytosis and recruit neutrophils to release more AMPs. Furthermore, AMPs also take part in repair of injured skin and promote wound healing [10]. So, the addition of further AMPs could be good as therapeutic additives for skin diseases, and in the cosmetic industry, it might help to prevent the growth of pathogenic bacteria and to improve skin health.

In previous studies [11-15], we reported the expression, purification, characterization and activity of the LPcin-YK3 peptide, a cationic $\alpha$-helical antimicrobial analog peptide from bovine lactophoricin, and confirmed the possibility of using it as an antibiotic substitute. The LPcin-YK3 peptide was obtained by amino acid modifications to reduce the number of amino acids and increase antibiotic activity for industrial use of native LPcin, an antimicrobial peptide consisting of 23 amino acids of the lactophoricin $N$-terminal. In this study, various antimicrobial activity tests were conducted against Staphylococcus aureus, a Gram-positive bacterium and L-929 fibroblasts, a mouse fibroblast cell line, to further investigate the activity of LPcin-YK3 peptide in more realistic environments. We also examined the hemolytic activity of LPcin-YK3 peptide against mouse erythrocytes to confirm its safety and how it affects the actual bacterial surfaces using scanning electron microscopy. The aim of this study was to evaluate the antimicrobial activity of LPcin-YK3 peptide as an alternative additive to synthetic ingredients used for cosmetic products.

\section{Materials and Methods}

\section{Expression and Purification of LPcin-YK3 Peptide}

The recombinant protein containing a ketosteroid isomerase (KSI) fusion partner and $\mathrm{His}_{6}$-tag to facilitate purification, was expressed in a mutant Escherichia coli C41(DE3) strain (Novagen, Darmstadt, Germany), as described previously [11, 14]. The cells were cultured in Luria-Bertani (LB) medium containing carbenicillin and transferred to M9 minimal medium and induced with $1 \mathrm{mmol} / \mathrm{l}$ isopropyl $\beta$-D-1-thiogalactopyranoside (IPTG, Amresco, USA) addition. The LPcin-YK3 peptide was finally purified by reverse-phase high-pressure liquid chromatography (RP-HPLC) (Waters Binary 1525, USA).

\section{Structural Characterization of LPcin-YK3 Peptide}

The correct molecular mass of the purified LPcin-YK3 peptide was confirmed by 4800 plus MALDI-TOF/TOF MS (Matrix assisted laser desorption/ionization time-of-flight mass spectrometry) Analyzer (AB Sciex, USA). The $\alpha$-cyano-4-hydroxycinnamic acid (CHCA, Sigma, USA) matrix was used and dissolved in $30 \%$ acetonitrile and $0.1 \%$ trifluoroacetic acid (TFA). The external standard $\beta$-galactosidase for calibration and LPcin-YK3 peptide were dissolved in the matrix solution, respectively, and these were loaded on the plate using the dried droplet method. The mass spectrum of the LPcin-YK3 peptide was acquired after averaging 1000 laser shots in positive ion reflector mode with the mass range of 799-4013 dalton (Da). We also confirmed the reproducibility of the spectrum by repeatedly measuring the separately spotted samples. Automated de novo peptide sequencing of the major peak was performed by calculation of the ion series of spectra using Top Down Sequencing (In-source decay). De novo 4000 Explorer Software was used for homology searches between obtained sequences and databases.

Circular dichroism (CD) spectrum was recorded using a Jasco J715 spectropolarimeter with a $1 \mathrm{~mm}$ path-length quartz cell for determination of the secondary structural features of the LPcinYK3 peptide as previously reported [13, 14]. Wavelengths were measured from 190 to $260 \mathrm{~nm}$ (in the far UV range) and $1 \mathrm{~nm}$ bandwidth at $0.2 \mathrm{~nm}$ step resolution with 20 mdeg sensitivity and $50 \mathrm{~nm} / \mathrm{min}$ speed. Each spectrum was obtained as an average of five scans with a response time of $0.25 \mathrm{~s}$ at ambient temperature, and the baseline was corrected by subtracting the measurement of the buffer without the peptide. The effect of the membrane environment on the conformation of the LPcin-YK3 peptide was determined by measurement in the absence or the presence of 20 , 40, 60, 80, and $100 \mathrm{mmol} / 1$ dodecylphosphocholine (DPC) micelles.

\section{Antimicrobial Assay of LPcin-YK3 Peptide}

The bacterial strain used in this study was S. aureus KCTC 1621, isolated from a clinical source. Stock culture of this strain was routinely stored on an Eggerth-Gagnon (EG) liver extract-fields slant at $-70^{\circ} \mathrm{C}$ and subcultured on an EG agar (Eiken Chemical, Japan), when required. The plates were incubated aerobically at $37^{\circ} \mathrm{C}$ for $16 \mathrm{~h}$ in an anaerobic chamber. The bacteria were then grown in LB medium broth ( $\mathrm{pH}$ 6.8). The antimicrobial activities of the LPcin-YK3 purified from the $\mathrm{pET}$ peptide expression system 31 , and the two commercial peptides against $S$. aureus were assayed in vitro by the cell counting method [31]. The positive control peptides, magainin, and melittin were purchased from Sigma (USA). The concentration of each peptide was determined by the Lowry method [32] using bovine serum albumin as standard. An aliquot $(100 \mu \mathrm{l})$ of the bacterial suspensions was mixed with LPcin-YK3 $(80 \mu \mathrm{g} / \mathrm{ml})$ diluted in distilled water to make a final volume of $200 \mu \mathrm{l}$ (final concentration, $40 \mu \mathrm{g} / \mathrm{ml}$ ). The experiment of the control condition was performed with distilled water, which exhibited no adverse effect on the organism used. The mixture was incubated aerobically at $37^{\circ} \mathrm{C}$ for $10 \mathrm{~min}$. Subsequently, the mixture was serially diluted with distilled water, and the aliquot $(50 \mu \mathrm{l})$ was placed on the LB agar surface with the test bacteria. All tests were performed in triplicate. Antimicrobial activity was defined as the common logarithm of the ratio of the number of colony-forming units under the control condition $\left(\mathrm{N}_{\mathrm{c}}\right)$ to that under the test condition $\left(\mathrm{N}_{\mathrm{t}}\right)$. The equation 
of antimicrobial activity is expressed as $\log \left(\mathrm{N}_{\mathrm{c}} / \mathrm{N}_{\mathrm{t}}\right)$.

Cell viability was determined by measuring the permeability of the peptide to Candida albicans KCTC 7270 membrane using the propidium iodide (PI) staining method. This method is based on the principle that PI cannot penetrate cell membranes of living cells, while cell membranes of dead cells permeate and combine with nuclei to show strong fluorescence. $C$. albicans cells were treated with LPcin-YK3 peptide and amphotericin B, an antifungal agent widely used for serious fungal infections, for $15 \mathrm{~min}$ and stained with PI. Images of PI stained nuclei were observed using a fluorescence microscope by excitation at $536 \mathrm{~nm}$ and emission at $623 \mathrm{~nm}$.

The minimum inhibitory concentration (MIC) assay was performed by constantly decreasing the concentration of each peptide to microbial rich broth in a series of tubes. It was used to measure the MIC of each peptide, which is the lowest concentration of each peptide that will inhibit the growth of microbes. The single colony of each strain was inoculated into LB, brain heart infusion (BHI), and potato dextrose agar (PDA) medium broth for a concentration of $10^{3}-10^{4}$ colony-forming units $/ \mathrm{ml}$. Peptides were added to each culture at various concentrations up to $0.04 \mu \mathrm{g} / \mathrm{ml}$. The control cultures were performed in medium broth corresponding to each strain without peptide. The microbial growth was assessed by increasing in optical density at a wavelength of $600 \mathrm{~nm}\left(\mathrm{OD}_{600}\right)$ after $18 \mathrm{~h}$. The absorbance of each culture was determined using an enzymelinked immunosorbent assay (ELISA) reader (EnSpire Multimode Reader, PerkinElmer Inc, USA). Finally, MIC values were obtained by fitting $\mathrm{OD}_{600}$ absorbance versus peptide concentration data using SigmaPlot.

The morphological changes of $S$. aureus induced by the LPcinYK3 were observed with a scanning electron microscopy (SEM). The strains were fixed with $2 \%$ glutaraldehyde and $2 \%$ paraformaldehyde in $0.1 \mathrm{~mol} / 1$ phosphate buffer ( $\mathrm{pH} \mathrm{7.4,} \mathrm{PB),} \mathrm{for}$ $6 \mathrm{~h}$ and washed two times for $30 \mathrm{~min}$ in $0.1 \mathrm{~mol} / 1 \mathrm{~PB}$. The strains were postfixed with $1 \%$ osmium tetroxide dissolved in $0.1 \mathrm{~mol} / 1$ PB for $2 \mathrm{~h}$ and dehydrated in ascending gradual series (50-100\%) of ethanol. It was followed by infiltrates of isoamyl acetate and subjected to critical point dryer (HCP-2, Hitachi, Japan). The strains were then coated with gold by ion sputter (IB-3 Eiko, Japan). The coated samples were examined and photographed with a high-resolution field emission SEM (FE-SEM, Hitachi, Japan) on the acceleration voltage of $20 \mathrm{kV}$ at the Korea Basic Science Institute (KBSI), Western Seoul center (Korea).

\section{Hemolytic Activity Assay of LPcin-YK3 Peptide}

Hemolytic activity assay was performed as described [33]. Freshly drawn mouse erythrocytes were rinsed three times with phosphate-buffered saline (PBS) and suspended in PBS to $8 \%$ $(v / v)$. The erythrocyte suspension was seeded into 96-well culture plates and then incubated with various concentrations of peptides for $1 \mathrm{~h}$ at $37^{\circ} \mathrm{C} .0 .1 \%(\mathrm{v} / \mathrm{v})$ Triton $\mathrm{X}-100$ was used as $100 \%$ hemolytic activity control. The supernatant was collected after another $1 \mathrm{~h}$ of incubation. The erythrocyte suspension was centrifuged at $270 \times g$ for $15 \mathrm{~min}$. The absorbance at a wavelength of $414 \mathrm{~nm}$ was examined by using an ELISA reader. The erythrocyte hemolysis percentage was calculated with the following equation [34]:

Hemolysis equation $(\%)=\{($ Sample absorbance - PBS absorbance $) /$ $(0.1 \%$ Triton X-100 absorbance - PBS absorbance $)\} \times 100$

Hemoglobin release after peptide treatment was assessed by measurement of the sample absorbance. Positive and negative controls representing total or no hemolysis were obtained by treating mouse erythrocytes with $0.1 \%(\mathrm{v} / \mathrm{v})$ Triton $\mathrm{X}-100$ and PBS, respectively.

\section{Human Patch Test}

A total of 31 female subjects between the ages 33 and 54 were selected for the study according to the inclusion and exclusion criteria. All subjects provided informed consent in conformance with the Good Clinical Practice guidelines as outlined by the Declaration of Helsinki. The study evaluated the skin sensitization potential of the test product after epicutaneous applications under the occlusive patch. The subjects visited the Ellead Co., Ltd. for a total of 4 times during 8 days. For both induction and challenge phases, approximately $35 \mu \mathrm{l}$ of the test product was applied to each designated site on the back between the shoulder blades and the waist, after the areas were washed with $70 \%$ ethanol. The test products were applied in a Van Der Bend Patch Test Chamber (Van der Bend, Brielle, Netherlands). The patches were allowed to remain in direct contact with the skin for a period of $48 \mathrm{~h}$. Subsequently, each designated site on the same subject was observed after $0.5,24$, and $120 \mathrm{~h}$, respectively. All experimental protocols were developed according to the ethical and animal welfare corporate principles of Ellead Co., Ltd. The experimental protocols were approved by the Ethics Commission of Ellead Co., Ltd. (number: EL-160215113S028-01; March 18, 2016).

\section{Statistical Analysis}

All data represent the mean value \pm standard deviation for each treatment group in a given experiment. All experiments were performed at least three times independently. Treatment groups were compared with the appropriate control group, and statistical significance was evaluated using a two-tailed paired $t$-test. The difference was considered significant at $p<0.05$.

\section{Results}

\section{Expression and Purification of LPcin-YK3}

We constructed the LPcin-YK3 expression system in E. coli using the KSI as a fusion protein to express a high yield of the peptide. The DNA oligomer sequence and amino acid sequence of LPcin-YK3 used for peptide-KSI fused construction are summarized in Fig. 1. Because this 


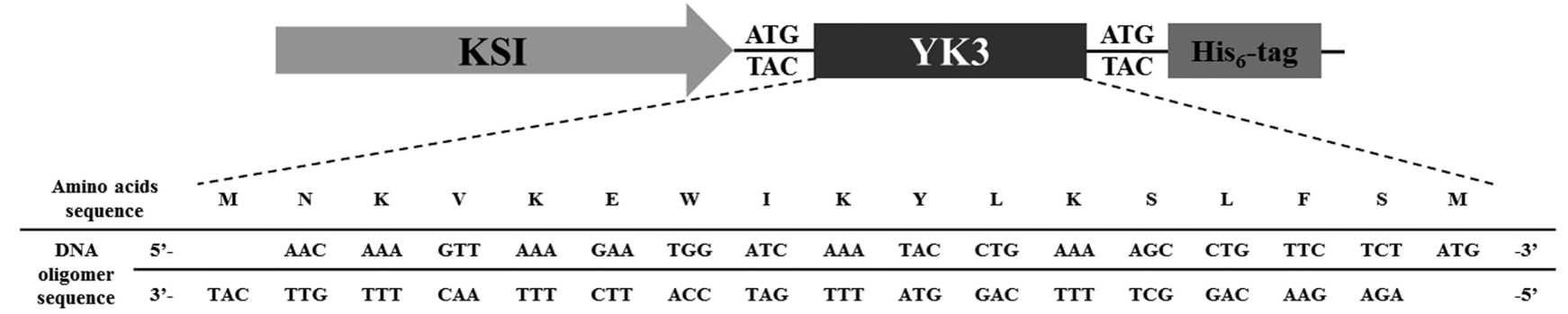

Fig. 1. Schematic diagram of the expression vector of LPcin-YK3 in the pET31b(+) vector.

The methionine residue for $\mathrm{CNBr}$ cleavage is located to isolate the target peptide. The sequences of amino acid and DNA are below the schematic diagram.

system has an insoluble KSI fusion protein, the target peptide was expressed as inclusion bodies, which reduced its toxicity to bacteria and the presence of tandem repeats increased the yield of the short peptide [16, 17]. The $\mathrm{His}_{6}{ }^{-}$ tag, located at the C-terminal, enables the purification of the fusion protein under denaturing conditions and the

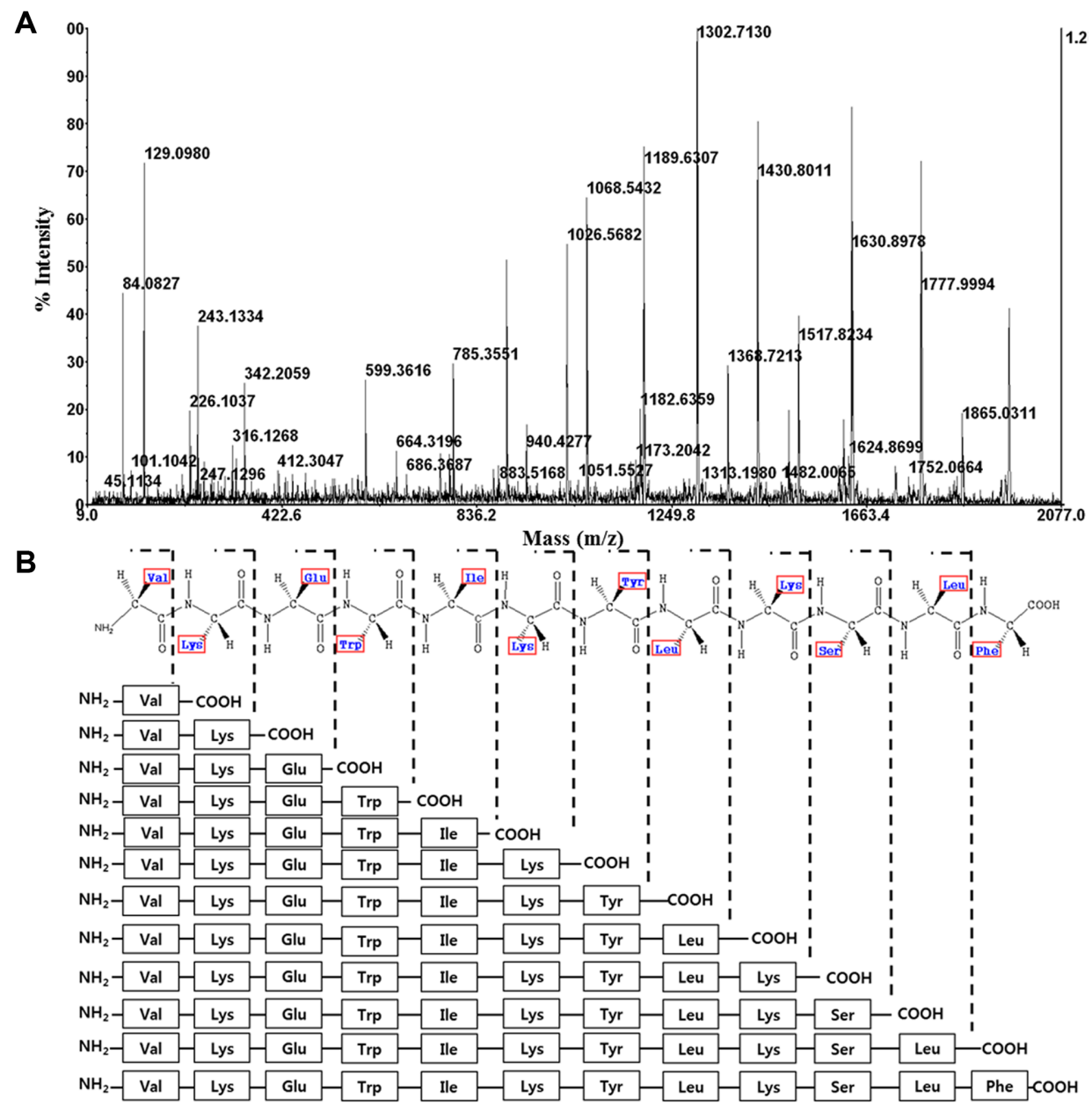

Fig. 2. Tandem mass analyses of LPcin-YK3.

(A) De novo sequencing of LPcin-YK3. The peptide is sequenced by calculating the difference in molecular weight between neighboring peaks. (B) The $\mathrm{m} / \mathrm{z}$ of the precursor ion was 1987.99 and the partial peptide sequence "VKEWIKYLKSLF" was determined using an automatic calculation method. 
methionine residues for cyanogen bromide (CNBr) cleavage are located at both ends of the peptide. The abovementioned experimental results can be found in reference 14 .

\section{Structural Characterization of LPcin-YK3}

The purity and identity of the final peptide were confirmed by MALDI-TOF mass spectrometry. The molecular weights of the homoserine lactone form and the homoserine free acid form of the LPcin-YK3 peptide after CNBr cleavage were 1,966.32 $\mathrm{Da}$ and 1,984.33 $\mathrm{Da}$, respectively. The result indicated that the molecular weight of LPcin-YK3 matched well with the theoretical molecular weight and the purification was successful without further contamination (refer to [14]). In addition, the amino acid sequence of the LPcin-YK3 peptide was confirmed by de novo sequencing using tandem mass spectrometry (MS/MS), which provides information on the primary sequence of the peptide (Fig. 2). Automated de novo sequencing from MS/MS confirmed that the partial sequence of the purified peptide ranged from 3 to 14 of the LPcin-YK3 peptide sequence (VKEWIKYLKSLF).

In order to examine the secondary structure and the behavior of the peptide in a membrane environment, $C D$ spectra of LPcin-YK3 peptide were measured in the absence and presence of various DPC concentrations. Generally, unordered peptides have one negative band near $195 \mathrm{~nm}$. $\alpha$-helical structures have two negative bands at 208 and $222 \mathrm{~nm}$ and a positive band at $192 \mathrm{~nm}$, whereas $\beta$-sheet structures show a negative band at $218 \mathrm{~nm}$ and a positive band at $195 \mathrm{~nm}[18,19]$. The six curves depicted in Fig. 3A show that the LPcin-YK3 peptide is a random coil in aqueous solution and forms an $\alpha$-helical structure in the presence of DPC. We observed no significant secondary structural changes in the peptide at various DPC concentrations (Fig. 3B), and thus we suggested that the peptide had a stable $\alpha$-helical structure in the presence of DPC micelles.

\section{Antimicrobial Assay of LPcin-YK3}

In the previous study, the antimicrobial spectrum of the recombinant peptides, LPcin-I and LPcin-II, was analyzed against five bacterial strains, including two Gram-positive and three Gram-negative strains using the agar hole diffusion method. At this point, the activities of the recombinant antimicrobial peptides were determined by examining the size and clearance of the inhibitory zone ie, corresponding to qualitative analysis [13]. In contrast to use of the agar hole diffusion method in the previous study, we selected the surface count plate method for the quantitative analysis of microbes. The advantage of this method is that the colonies stay small and compact, and it gives reliable and consistent results.

In this study, in order to develop new and safer types of antimicrobial agents, we assessed the growth-inhibitory effects of LPcin-YK3 against S. aureus, a Gram-positive bacterium. Additionally, we compared the results with the antimicrobial activities of commercially available
A

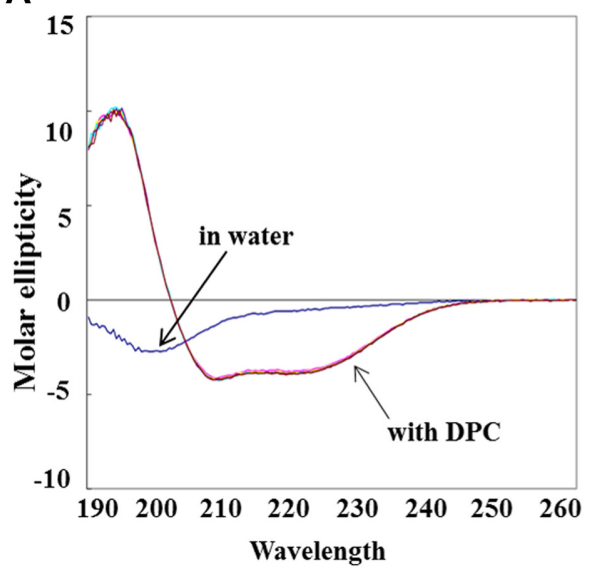

B

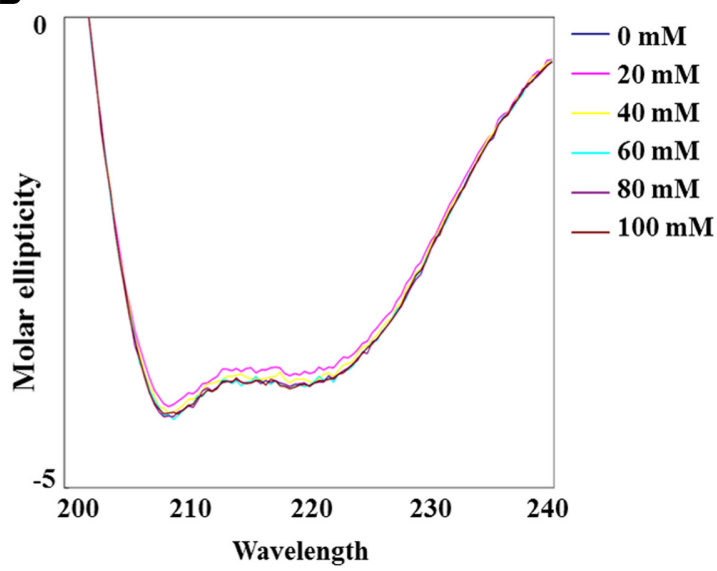

Fig. 3. Circular dichroism spectra of LPcin-YK3.

(A) CD spectrum of the LPcin-YK3 peptide in water and in DPC micelle environment. The conformation of the peptide is a random coil when only water is present, whereas a $\alpha$-helix structure in the presence of DPC. (B) An enlarged view of the 200-240 nm region in CD spectra at different DPC concentration. All spectra in the presence of DPC micelles show minima at 208 and $222 \mathrm{~nm}$ along with maxima at $192 \mathrm{~nm}$, characteristic of $\alpha$ helical secondary structure. 


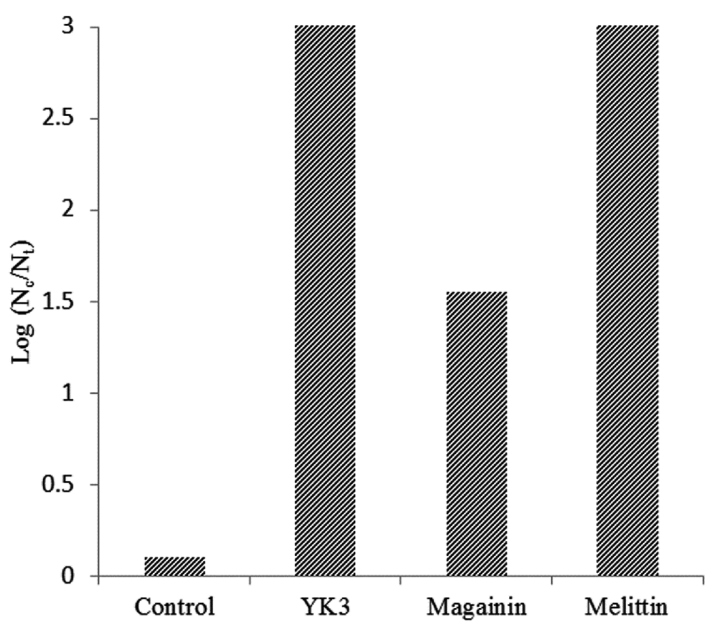

Fig. 4. Antimicrobial activity for LPcin-YK3, magainin, and melittin against Staphylococcus aureus.

The activity was evaluated by the common logarithm of the ratio of the number of colony-forming units under the control condition $\left(\mathrm{N}_{\mathrm{c}}\right)$ to that under the test condition $\left(\mathrm{N}_{\mathrm{t}}\right)$.

antimicrobial agents (magainin, melittin). In routine screening, the LPcin-YK3 at $40 \mu \mathrm{g} / \mathrm{ml}$ exhibited a potent inhibiting activity against $S$. aureus. Melittin exhibited highly microbicidal behavior and had similar antimicrobial activity to that of LPcin-YK3, while the activity value of magainin peptide decreased to less than $50 \%\left[\log \left(\mathrm{N}_{\mathrm{c}} / \mathrm{N}_{\mathrm{t}}\right.\right.$ : 1.55] of the LPcin-YK3 and melittin, and no activity was observed in the control culture (Fig. 4).

We examined the effect of LPcin-YK3 on the fungal pathogen $C$. albicans using PI staining. When the cell membrane of $C$. albicans is destroyed by an antimicrobial peptide or antifungal drug, the fluorescent dye PI can enter the cell and bind to the DNA, resulting in red fluorescence. C. albicans cells were treated with LPcin-YK3 and antifungal
Table 1. MIC data for LPcin-YK3, magainin and melittin against $S$. aureus.

\begin{tabular}{lc}
\hline Peptides & Minimum inhibitory concentration $(\mu \mathrm{g} / \mathrm{ml})$ \\
\hline LPcin-YK3 & 0.62 \\
Magainin & 20.00 \\
Melittin & 0.15 \\
\hline
\end{tabular}

agent amphotericin B for the same time, but increased PI fluorescence showing membrane permeability only in LPcin-YK3 treated cells (Fig. 5). No PI fluorescence was seen in cells treated with control and amphotericin $B$, indicating that LPcin-YK3 induces cell death of C. albicans more rapidly than amphotericin B. Amphotericin B is the primary drug used to treat an extensive of systemic fungal infections, but is used only for patients suffering from serious infections due to vast and potentially lethal side effects. Our cell viability studies suggest that LPcin-YK3 may be an effective and safe alternative to amphotericin $B$ in the treatment of fungal infections. To confirm this, we will carry out a study on the activity of LPcin-YK3 against various fungal pathogens.

In microbiology, the minimum inhibitory concentration (MIC) is the lowest concentration of a chemical that prevents the visible growth of a bacterium. From the clinical perspective, culturing the organism infecting a patient with available antibiotic drugs and determining the MICs is very important for identifying the correct drug to actually give to the patient [7]. Therefore, we have found that it is necessary to quantify the exact MIC value of LPcin-YK3 toward S. aureus and to compare this data with other peptides. The MICs of the isolated LPcin-YK3 and commercial peptides, magainin, and melittin, against S. aureus, were shown in Table 1. In liquid growth inhibition, the purified LPcin-YK3 had marked activity (MIC: $0.62 \mu \mathrm{g} / \mathrm{ml}$ )

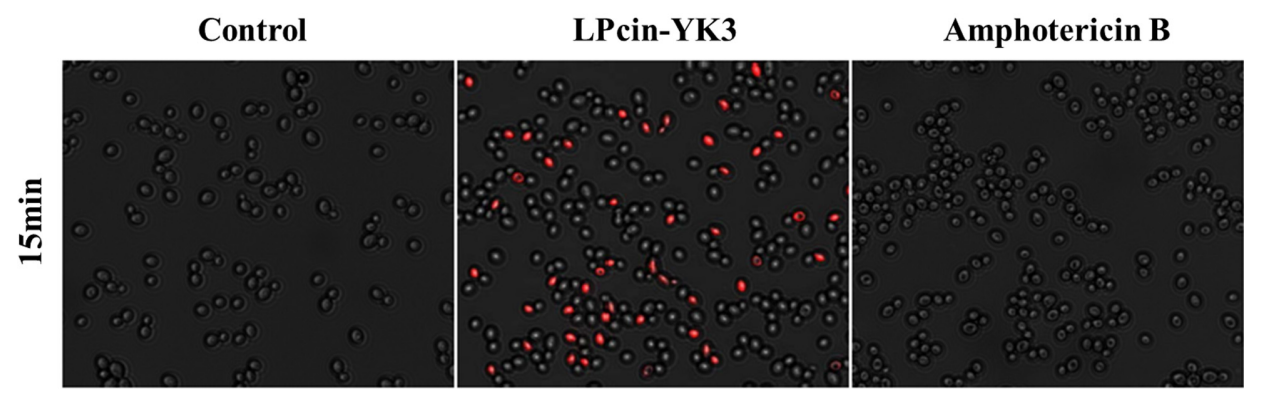

Fig. 5. Effects of LPcin-YK3 and amphotericin B on the cytoplasmic membrane of Candida albians cells.

A fluorescence microscope image of dead cell nuclei stained with propidium iodide is shown. When C. albicans was treated at the same time, it was confirmed that LPcin-YK3 induces cell death more rapidly than amphotericin B. 
against the Gram-positive strain, S. aureus. The other positive peptides, magainin, a family of the antimicrobial peptide from Xenopus skin [20] and melittin, a potent microbicide, exhibited entirely different MIC values (MIC: $20 \mu \mathrm{g} / \mathrm{ml}$ and $0.15 \mu \mathrm{g} / \mathrm{ml}$ for magainin and melittin, respectively). In addition, LB-medium corresponding to the negative control did not cause any adverse effects on the growth of S. aureus.

Furthermore, the MIC values of LPcin-YK3 against four bacteria and one fungus were determined by testing concentrations of pure LPcin-YK3 in liquid growth inhibition assay (Table 2). Except for C. albicans fungus strain, antimicrobial activities of all bacterial strains tested by LPcin-YK3 are very similar to the within a MIC of 1.25 or $0.62 \mu \mathrm{g} / \mathrm{ml}$, respectively. Unlike bacterial strains, it should be noted that a $C$. albicans strain appear to be resistant to LPcin-YK3 resulting in MIC value of $10 \mu \mathrm{g} / \mathrm{ml}$. These results suggest that the LPcin-YK3 peptide has probably strong growth-inhibitory effects on prokaryotic bacteria than eukaryotic fungi with a hardy cell wall. In this regard, further work is necessary to establish whether this activity is still weak activity in vitro after the attack of eukaryotic cell by LPcin-YK3.

Based on the potent antimicrobial activity of the LPcinYK3 against $S$. aureus as mentioned above, SEM was used to examine the minor changes in cell morphology of S. aureus that have adapted to LPcin-YK3 (Fig. 6). The cells altered their morphologies in the presence of $40 \mu \mathrm{g} / \mathrm{ml}$ of LPcin-YK3. S. aureus cells were generally round-shaped with no alterations in the morphologies in the control (no added LPcin-YK3; Fig. 6A). However, morphological changes of $S$. aureus, including enlarged, malformed and rough-surfaced were induced by treatment with $40 \mu \mathrm{g} / \mathrm{ml}$ of LPcin-YK3 (Fig. 6B).

\section{Hemolytic Activity of LPcin-YK3}

Further evaluations of peptide toxicity were confirmed by mouse erythrocyte lysis and hemoglobin release due to its presence. The cells were treated with LPcin-YK3, magainin, and melittin. Melittin significantly increased dose-dependent release of hemoglobin following $1 \mathrm{~h}$
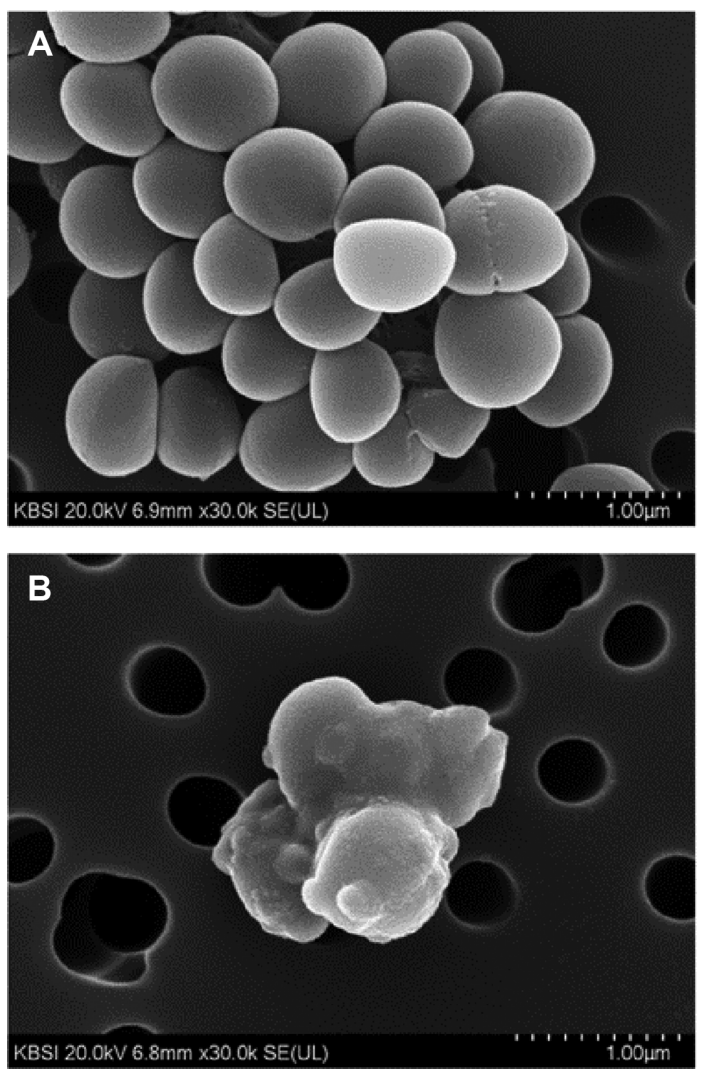

Fig. 6. SEM micrographs of Staphylococcus aureus treated with LPcin-YK3.

Morphological effect of S. aureus with no addition (A) and addition $(40 \mu \mathrm{g} / \mathrm{ml}(\mathbf{B}))$ of LPcin-YK3.

treatment of a mouse erythrocyte suspension. However, LPcin-YK3 and magainin had no effect on hemoglobin release in our study (Fig. 7A). Subsequently, hemolytic activities of LPcin-YK3, magainin, and melittin against mouse erythrocytes were quantified by a colorimetric assay. No hemolytic activity against mouse erythrocytes was observed with LPcin-YK3 and magainin used at different doses ie, 1, 10, and $40 \mu \mathrm{g} / \mathrm{ml}$. However, melittin caused severe hemolytic activity $(75 \%)$ at $40 \mu \mathrm{g} / \mathrm{ml}$ (Fig. 7B). Previous studies have indicated that melittin was reported to cayse inappropriate hemolytic activity [21]. The LPcin-

Table 2. MIC comparison of LPcin-YK3 peptide against various strains.

\begin{tabular}{cccccccc}
\hline Peptide & \multicolumn{9}{c}{ Organism $^{\text {a }}$} \\
\cline { 2 - 8 } MIC $(\mu \mathrm{g} / \mathrm{ml})$ & E. coli & P. gingvalis & S. mutans & S. aureus & P. acnes & C. albicans \\
\hline LPcin-YK3 & 1.25 & 0.62 & 1.25 & 0.62 & 1.25 & 10.0 \\
\hline
\end{tabular}

${ }^{a}$ Gram-negative strain: Escherichia coli KCCM 41290, Porphyromonas gingvalis KCTC 5352; Gram-positive strain: Streptococcus mutans KCCM 40105, Staphylococcus aureus KCTC 1621, Propionibacterium acnes KCCM 41747; Fungus strain: Candida albicans KCTC 17712. 
A

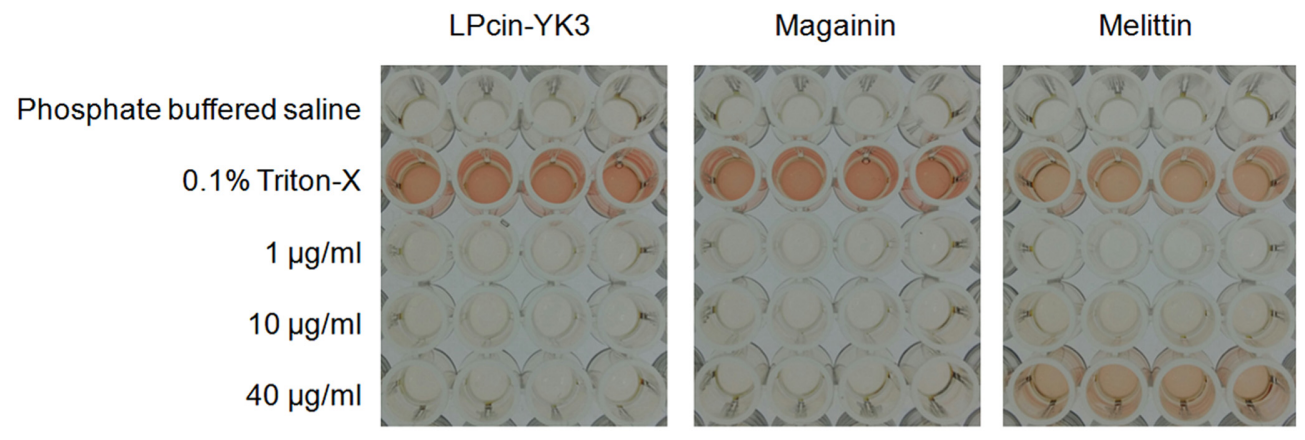

B LPcin-YK3
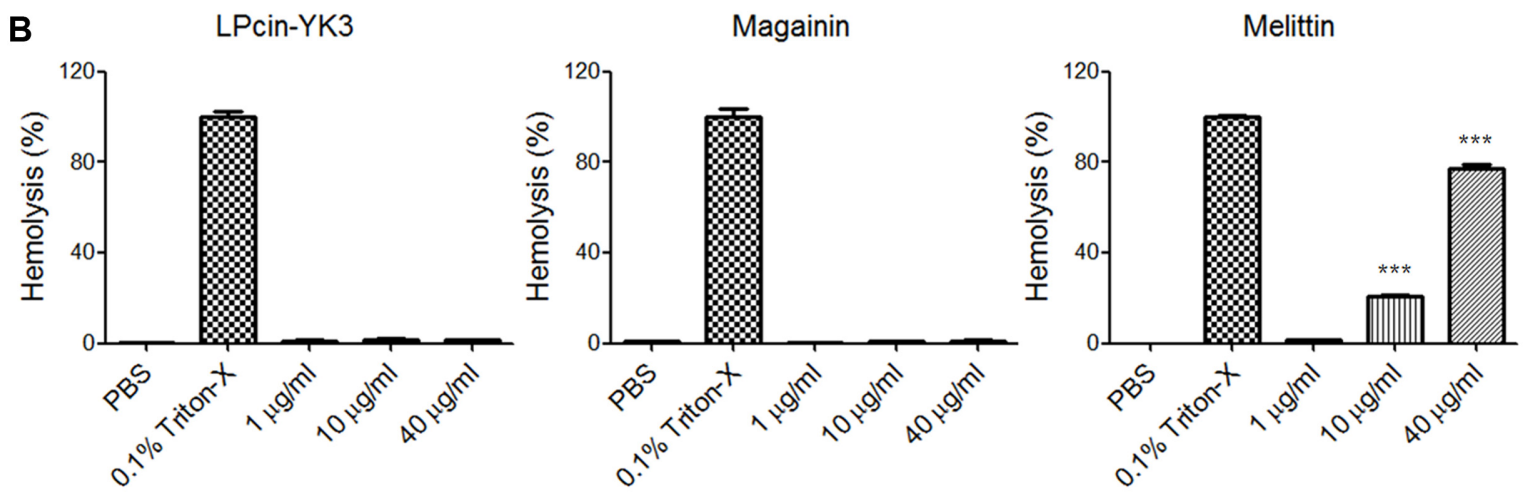

Fig. 7. Hemolytic activities for LPcin-YK3, magainin and melittin peptides.

The hemolytic percent was calculated by the following equation $(\%)=\{($ Abs $414 \mathrm{~nm}$ at the peptide treatment $-\mathrm{Abs} 414 \mathrm{~nm}$ at PBS)/(Abs $414 \mathrm{~nm}$ at $0.1 \%$ Triton X-100 treatment-Abs $414 \mathrm{~nm}$ at PBS) $\} \times 100$, and the $0.1 \%$ of Triton X-100 was used as the control for $100 \%$ hemolysis. (A) Hemolytic morphology, (B) Hemolytic percentage, ${ }^{*}$ indicates significant difference at $p<0.05$ compared to PBS group.

YK3, magainin, and melittin also showed analogous hemolytic activities against human erythrocytes (data not shown).

\section{Human Patch Test}

The human patch test is a confirmatory test in the safety evaluation of skin sensitizers. It is concluded that where there is a specific rationale for testing, for example, to substantiate a no effect level for a sensitizing chemical, then rigorous independent review may confirm that a human patch test is ethical and scientifically justifiable. Under the conditions of the human patch test, there was no evidence of skin irritation or sensitization in any of the 31 subjects (Table 3). The results provide evidence $40 \mu \mathrm{g} / \mathrm{ml}$ LPcin-YK3 lacked the potential to sensitize the skin. We confirmed that LPcin-YK3 was not likely to induce skin irritation by the human patch test. These results suggest that LPcin-YK3 may potentially be used for cosmetics or drugs to treat skin infection and therapies related to skin sensitization disorders, and furthermore, that this peptide may be advantageous as it is a novel material with no adverse effects on human skin.

\section{Discussion}

The resistance of bacteria to misuse and abuse of existing antibiotics poses serious health problems. In addition, the number of new antibiotics developed by conventional

Table 3. Patch test according to the International Contact Dermatitis Research Group (ICDRG) for LPcin-YK3.

\begin{tabular}{cc}
\hline LPcin-YK3 $(40 \mu \mathrm{g} / \mathrm{ml})$ & Reactivity score $(n=31$, female $)$ \\
\hline $0.5 \mathrm{~h}$ & $0.0^{\mathrm{a}}$ \\
$24 \mathrm{~h}$ & 0.0 \\
$120 \mathrm{~h}$ & 0.0 \\
\hline
\end{tabular}

Peptide patch test is a well-established method of diagnosing contact dermatitis: a delayed type of hypersensitivity (type IV reaction). The procedure of the patch test can also be used before recommending alternative antimicrobial medicines and skin care products in a particular patient.

${ }^{a}$ Reactivity score: negative reaction, 0 ; doubtful or slight reaction, 0.5 ; weak (non-vesicular) positive reaction, 1; strong (vesicular) positive reaction, 2; and extreme positive reaction, 3 . 
methods is rapidly declining ie, there are fewer effective drugs available to combat the rising number of antibioticresistant "super" bacteria. AMPs are attracting attention worldwide as an alternative to these problems. Unlike conventional antibiotics, AMPs are derived from natural sources and have no resistance problems and are known to have no side effects when taken for a long time. Furthermore, the advantage of AMPs is that they have broad antimicrobial activity not only against Grampositive and Gram-negative bacteria (can kill bacteria much faster than most conventional antibiotics), but also against fungi $[22,23]$.

In this study, we designed a new AMP, LPcin-YK3, based on lactophoricin, a natural AMP found in bovine milk. The LPcin-YK3 peptide is superior to the original peptide in antimicrobial activity and has a short amino acid length of 15 mer instead of 23 mer, suitable for industrial use. Starting with DNA annealing, the peptide was successfully expressed, separated and purified and finally, high-purity peptides were obtained at a yield of 8 to $10 \mathrm{mg} / 1$. Purified peptides were identified and characterized using MALDITOF mass spectrometry (MS) and circular dichroism spectroscopy. The $m / z$ value measured by MS was in good agreement with the theoretical molecular weight of LPcinYK3, and the partial sequence of the peptide was confirmed by de novo sequencing using MS/MS. The secondary structure of the peptides studied using CD has a stable $\alpha$ helical conformation in the DPC micelle environment.

We also analyzed the morphological changes of $S$. aureus induced by LPcin-YK3 using SEM based on its potential for penetrating and disrupting the membrane. In our study, the cell morphology of LPcin-YK3 treated cells of S. aureus under SEM provided strong evidence that the presence concentration $(40 \mu \mathrm{g} / \mathrm{ml})$ of LPcin-YK3 is distress for the bacterial populations, characterized by the large size (Fig. 6B). These structural changes suggests that major antimicrobial action of LPcin-YK3 was performed by interaction with negatively charged membrane elements of bacteria through conventional processing mechanisms, which are membrane breakdown as observed in the helixforming amphipathic antimicrobial peptides [24-26].

It is hard to predict whether the antimicrobial peptides will be safe in vivo based on the results gained in vitro. Nonetheless, our goal is finding a safe peptide to select as good candidates for a clinical trial. To be excellent AMPs, they selectively kill pathogenic microorganisms without being significantly toxic to host cells. For example, magainin discovered in the skin of the African clawed frog, Xenopus laevis, inhibits bacterial growth in the concentration range
$<50 \mu \mathrm{mol} / \mathrm{l}$. However, the concentration at which it causes $\mathrm{HC}_{50}$ in human erythrocytes is as high as 1,000 $\mu \mathrm{mol} / 1$ [27]. Another peptide, melittin exhibited severe toxic effects against erythrocytes and mammalian cells at an analogous concentration $(\sim 40 \mu \mathrm{g} / \mathrm{ml})$ resulting in the highly hemolytic activity of the tested antimicrobial peptides (Fig. 7). These results are similar other references proving high toxicity of melittin [28]. From the safety perspective, our data demonstrate that LPcin-YK3 is even significantly less hemolytic activity than melittin. Nevertheless, the LPcinYK3 which exhibits powerful antimicrobial activity is possible without a corresponding increase in hemolytic activity. As a result, LPcin-YK3 might expect to be a safe substitute for antimicrobial treatment.

Among staphylococci, a gram-positive bacterium, S. aureus has long been recognized as one of the most important bacteria to cause disease in humans. It is the leading cause of skin and soft tissue infections such as abscesses, furuncles, and cellulitis [29]. Indeed, the reactivity score of LPcin-YK3 for human skin in vivo means the potential for safe AMP (Table 3). In particular, S. aureus is extremely prevalent in individuals with atopic dermatitis in a study of cosmetic development [30]. The presence of S. aureus in individuals with atopic dermatitis is not an indication to treat with oral antibiotics, as evidence has not shown this to benefit the patient [30]. Accordingly, LPcin-YK3 was identified as one of the AMPs with desirable properties ie, either to inhibit the growth of potential pathogens such as staphylococci and/or to increase the function of the defense mechanisms of the immune system in the human skin [9]. In this regard, LPcin-YK3 can be considered as a source of antimicrobial useful for atopic dermatitis applications.

In conclusion, the present results indicate that bovine lactophoricin-derived peptide has an inhibitory effect against specific $S$. aureus in vitro. This information is expected to help elucidate and augment the positive biological effects of LPcin-YK3 indicating its low acute toxicity to human erythrocytes. More importantly, the inhibitory action of LPcin-YK3 against S. aureus could be as potential therapeutics for the treatment of diseases caused by $S$. aureus. From a dermatological perspective, further study will be required to establish with precision the relevance of LPcin-YK3 in a clinical trial for patients with atopic dermatitis.

\section{Ethics Approval and Consent to Participate}

Human patch test was developed according to the ethical and animal welfare corporate principles of Ellead Co., Ltd. 
The experimental protocols were approved by the Ethics Commission of Ellead Co., Ltd. (number: EL-160215113S02801; March 18, 2016).

\section{Acknowledgments}

This work was supported by the Industrial Core Technology Development Program (10052915, Development of Antimicrobial or Anti-inflammatory peptides for skin care products) funded by the Ministry of Trade, Industry \& Energy (MOTIE, Korea) and by Basic Science Research Program through the National Research Foundation of Korea (NRF) funded by the Ministry of Education (2017012599).

\section{Conflict of Interest}

The authors have no financial conflicts of interest to declare.

\section{References}

1. Brogden KA. 2005. Antimicrobial peptides: pore formers or metabolic inhibitors in bacteria? Nat. Rev. Microbiol. 3: 238-250.

2. Liu Y, Luo J, Xu C, Ren F, Peng C, Wu G, Zhao J. 2000. Purification, characterization, and molecular cloning of the gene of a seed-specific antimicrobial protein from pokeweed. Plant Physiol. 122: 1015-1024.

3. Chernysh S, Kim SI, Bekker G, Pleskach VA, Filatova NA, Anikin VB, et al. 2002. Antiviral and antitumor peptides from insects. Proc. Natl. Acad. Sci. USA 99: 12628-12632.

4. Hancock RE, Sahl HG. 2006. Antimicrobial and host-defense peptides as new anti-infective therapeutic strategies. Nat. Biotechnol. 24: 1551-1557.

5. Zasloff M. 2002. Antimicrobial peptides of multicellular organisms. Nature 415: 389-395.

6. Rydlo T, Miltz J, Mor A. 2006. Eukaryotic antimicrobial peptides: promises and premises in food safety. J. Food Sci. 71: R125-R135.

7. López-Meza JE, Ochoa-Zarzosa A, Barboza-Corona JE, Bideshi DK. 2015. Antimicrobial peptides: current and potential applications in biomedical therapies. Biomed. Res. Int. 2015: 367243.

8. Rahnamaeian M, Vilcinskas A. 2015. Short antimicrobial peptides as cosmetic ingredients to deter dermatological pathogens. Appl. Microbiol. Biotechnol. 99: 8847-8855.

9. Kenshi Y, Gallo RL. 2008. Antimicrobial peptides in human skin disease. Eur. J. Dermatol. 18: 11-21.

10. Bardan A, Nizet, Gallo RL. 2004. Antimicrobial peptides and the skin. Expert. Opin. Biol. Ther. 4: 543-549.

11. Park TJ, Kim JS, Choi SS, Kim Y. 2009. Cloning, expression, isotope labeling, purification, and characterization of bovine antimicrobial peptide, lactophoricin in Escherichia coli. Protein Expr. Purif. 65: 23-29.

12. Kim JS, Park TJ, Kim Y. 2009. Optimized Methods for purification and NMR measurement of antibacterial peptide, bovine lactophoricin, J. Korean Magn. Reson. Soc. 13: 96-107.

13. Park TJ, Kim JS, Ahn HC, Kim Y. 2011. Solution and solidstate NMR structural studies of antimicrobial peptides LPcin-I and LPcin-II. Biophys. J. 101: 1193-1201.

14. Kim JS, Jeong JH, Kim KS, Kim Y. 2015. Optimized expression and characterization of antimicrobial peptides, LPcin analogs. Bull. Korean Chem. Soc. 36: 1148-1154.

15. Jeong JH, Kim JS, Choi SS, Kim Y. 2016. NMR structural studies of antimicrobial peptides: LPcin analogs. Biophys. J. 110: $423-430$

16. Cipáková I, Gasperík J, Hostinová E. 2006. Expression and purification of human antimicrobial peptide, dermcidin, in Escherichia coli. Protein Expr. Purif. 45: 269-274.

17. Sharpe S, Yau WM, Tycko R. 2005. Expression and purification of a recombinant peptide from the Alzheimer's $\beta$-amyloid protein for solid-state NMR, protein expression and purification. Protein Expr. Purif. 42: 200-210.

18. Greenfield NJ. 2006. Using circular dichroism spectra to estimate protein secondary structure. Nat. Protoc. 1: 2876-2890.

19. Gopal R, Park JS, Seo CH, Park Y. 2012. Applications of circular dichroism for structural analysis of gelatin and antimicrobial peptides. Int. J. Mol. Sci. 13: 3229-3244.

20. Zasloff M. 1987. Magainins, a class of antimicrobial peptides from Xenopus skin: isolation, characterization of two active forms, and partial cDNA sequence of a precursor. Proc. Natl. Acad. Sci. USA 84: 5449-5453.

21. Sovadinova I, Palermo EF, Urban M, Mpiga P, Caputo GA, Kuroda K. 2011. Activity and mechanism of antimicrobial peptide-mimetic amphiphilic polymethacrylate derivatives. Polymers 3: 1512-1532.

22. Hancock RE, Falla T, Brown MH. 1995. Cationic antibacterial peptides. Adv. Microb. Physiol. 37: 135-75.

23. Piers KL, Brown MH, Hancock RE. 1994. Improvement of outer membrane-permeabilization and lipopolysaccharidebinding activities of an antimicrobial cationic peptide by Cterminal modification. Antimicrob. Agents Chemother. 38: 2311-2316.

24. Odell EW, Sarra R, Foxworthy M, Chapple DS, Evans RW. 1996. Antibacterial activity of peptides homologous to a loop region in human lactoferrin. FEBS Lett. 382: 175-178.

25. Düring K, Porsch P, Mahn A, Brinkmann O, Gieffers W. 1999. The non-enzymatic microbicidal activity of lysozymes. FEBS Lett. 449: 93-100.

26. Ibrahim HR, Yamada M, Matsushita K, Kobayashi R, Kato A. 1994. Enhanced bactericidal action of lysozyme to Escherichia coli by inserting a hydrophobic pentapeptide into its Cterminus. J. Biol. Chem. 269: 5059-5063.

27. Matsuzaki K, Sugishita K, Harada M, Fujii N, Miyajima K. 1997. Interactions of an antimicrobial peptide, magainin 2, 
with outer and inner membranes of gram-negative bacteria. Biochim. Biophys. Acta 1327: 119-130.

28. Son DJ, Ha SJ, Song HS, Lim Y, Yun YP, Lee JW, et al. 2003. Melittin inhibits vascular smooth muscle cell proliferation through induction of apoptosis via suppression of nuclear factor-kappaB and Akt activation and enhancement of apoptotic protein expression. J. Pharmacol. Exp. Ther. 317: 627-634.

29. Tong SY, Davis JS, Eichenberger E, Holland TL, Fowler VG. 2015. Staphylococcus aureus infections: epidemiology, pathophysiology, clinical manifestations, and management. Clin. Microbiol. Rev. 28: 603-661.

30. Birnie AJ, Bath-Hextall FJ, Ravenscroft JC, Williams HC. 2008. Interventions to reduce Staphylococcus aureus in the management of atopic eczema. Cochrane Database Syst. Rev. (3): CD003871. doi: 10.1002/14651858.CD003871.pub2.

31. Masatoma M, Yasunori T, Yuji O, Katsunori M, Aya S,
Hajime U. 2001. Functional analysis of antibacterial activity of Bacillus amyloliquefaciens phage endolysin against Gram-negative bacteria. FEBS Lett. 500: 56-59.

32. Lowry OH, Rosebrough NJ, Farr AL, Randall RJ. 1951. Protein measurement with the Folin phenol reagent. J. Biol. Chem. 193: 265-275.

33. Evans BC, Nelson CE, Yu SS, Beavers KR, Kim AJ, Li H, et al. 2013. Ex vivo red blood cell hemolysis assay for the evaluation of $\mathrm{pH}$-responsive endosomolytic agents for cytosolic delivery of biomacromolecular drugs. J. Vis. Exp. (73): e50166. doi: 10.3791/50166.

34. Molly FC, Sean WD, Mark SW, Colleen MS, Scott AS, Don RP, et al. 2000. Standard practice for assessment of hemolytic properties of materials. American Society for Testing of Materials. ASTM F756-00. Available from: https://www. astm.org/DATABASE.CART/HISTORICAL/F756-00.htm 